\title{
Digital Reading Practices as a Factor in Identity Formation
}

\author{
Yuliia Polovynchak * [0000-0003-4903-5434], Viktoriia Bondarenko [0000-0002-1617-3665] \\ National Law Library V.I. Vernadskyi, Kyiv, Ukraine \\ *nub@nbuv.gov.ua
}

\begin{abstract}
The article is devoted to studying the influence of modern digital opportunities related to books and reading on the formation of a sense of belonging to the cultural and national community. Reading practices are seen as repetitive joint actions that are part of the formation of national identities. Representation in the national culture of the body of significant texts and the development of literary and reading infrastructure are seen as an important component of the cultural field. Modern information technologies intensify such processes and provide additional tools for them. Mobile applications are considered one of the tools of wide and scientifically supported access to significant national texts. The conclusion is substantiated the influence of the latest reading practices, on the formation of national identities as tools for involving individuals in the processes of shared experience and understanding of culture.
\end{abstract}

Keywords: reading, reading practices, identity, mobile applications, symbolic texts.

\section{INTRODUCTION}

The modern digital world has significantly influenced identities, while bringing up to date this issue in both the practical plane and reflections of intellectuals, as well as in scientific research.

In recent decades, against the background of discussions about the "archaic nature" of traditional identities and the formation of a global community, the active replacement of national identities by others supranational, subnational, religious ones, etc., there is a surge of modern nationalisms, emphasising the ability of the national identity to perform integration and mobilisation functions; exacerbation of conflicts against the background of ideological contradictions. Identities in the digital globalised world are changing as a phenomenon: some are blurring; others are intensifying in response to the threat of being blurred. At the same time, new or previously marginal identities appear or manifest.

Meanwhile, the actual processes of formation and experiencing of identities, building their hierarchies have changed, mainly due to the emergence of new practices, new means of communication and consolidation of communities. Cultural practices in the digital environment is among the areas that has changed. Since we consider identity as a phenomenon formed in cultural practices, the study of transformations of these practices will make it possible to clarify the modern specifics of the existence (functioning) of identities.

\section{RESEARCH METHODOLOGY}

The issue of reading practices as a problem of cultural studies is being brought up to date for several reasons. Firstly, research of changes in cultural practices with the introduction of communication technologies remains promising in general due to their significant impact on virtually the entire literary process - from writing books to their distribution and further comprehension. Secondly, as already mentioned, the globalisation and digitalisation of modern life significantly changes the identity-related (and hence all social) processes. Therefore, the study of reading as a component of the cultural life of the community, the way of forming such a community and the factor of its stability, adaptability, flexibility, openness gains newfound relevance.

The methods of humanities and information technology have been used in the research. The systematic method was used to substantiate the conjunction between the processes of national identification and cultural practices. The historical method has elucidated the evolution of reading practices. The result is a conclusion about the peculiarities of modern communications related to books and reading. Such features, in particular, determine their 
intensification, multimedia and mediation through Internet technologies.

The comparative method and the method of classification were used in the analysis of reader mobile applications and the selection of their main types.

The integration of humanities and information technology has provided research on mobile access technologies and the promotion of iconic books and authors.

\section{RESULTS OF THE RESEARCH}

Among cultural practices, we consider it necessary to highlight and pay attention to reading practices, by which we mean the traditional, repetitive activities of people or groups related to the choice, recommendations of books and texts for reading; their comprehension through discussion. An important result of such activities is the inclusion of the written and the read in public discourse - through both professional criticism and a number of the advanced digitally mediated amateur initiatives: reading clubs, recommendation and exchange communities, communities of supporters (fans) of some authors or texts, etc.

Ukrainian scientists are actively developing issues of both a general role of memory institutions in shaping the socio-cultural environment [1], and functioning and development of individual projects of integrated digital resources [2;3]. Technological aspects of creating and ensuring the functioning of such projects, taking into account modern requirements for digital library resources and sources of scientific information, have also been reflected in historiography [4]. Thus, the scientific challenge of digital representation of the national cultural heritage is being developed quite actively. However, given the dynamic development of digital resources, the constant emergence of new technologies and areas of work, scientific interest in the issue is preserved. At the same time, we can talk about the evolution of this interest - along with research on the formation of digital resources, the issue of support and management of digital information collections, their promotion is being brought up to date.

The influence of reading practices on the formation of national community is reflected in the scientific literature, mainly in research on the concept and specifics of the formation of national identities. Among the classic works on the consideration of nations and corresponding identities - "Imagined Communities" by Benedict Anderson [5] quite illustratively identifies "reading the same newspapers" as a factors in the formation of a stable national community. This criterion for sure cannot be considered as an absolute one, but the "newspapers" Anderson refers to are indeed a symbol of common time, space (a clear idea of the way "we have it" and the way it is "elsewhere"), literary language, content (common needs and interests).
Extending the idea of "shared reading" as an integrative factor, we are going to pay your attention to Gregory Juzdanis's opinion, who writes about the literary canon collection of texts recounting the story of the nation, facilitates the experience of solidarity by allowing people to see themselves as citizens of a unified nation, creating the identity of national culture [6].

The existing national, cultural or even generational canon defines reading the same books as a way and, at the same time, a marker of belonging to communities. It is worth agreeing with the opinion of Ukrainian researcher $\mathrm{O}$. Romanenko that "readers and writers are a kind of hermeneutic circle, a conditional and imaginary community that shares ideas, metaphors, images, creates common linguistic and literary codes, which set the tone and tempo to the existence of the ideas common to a particular generation." [7].

Such main, and, more importantly, - common national texts are fundamental to a sense of identity for a number of reasons: from attesting to the unity of senses ("we" reflect on the same texts, even coming to different conclusions and visions; the quotes from them become memetic and recognisable expressions); unity of language (culture is created by language with all its variations, which only testify to its universality for mutual understanding - literally - in the community); territorial unity (the list of canonical texts and their authors, as a rule, represent all regions and are equally known and understandable on all national territory); cultural unity (not only the common culture today, but also in its historical longevity, the creation based on the previous tradition)

This tradition, which involves a constant return to iconic books and names, the actualisation of classical texts through imitation, deconstruction, re-reading creates a common space - a cultural "place of memory." These reading practices, among other things, form markers by which the community will recognise itself, and, importantly, at the ordinary, unarticulated level, but no less, and perhaps even more influential (the importance and effectiveness of such household nationalism has been repeatedly emphasised by researchers) [8]. Thus, different versions of screenplays, "comicsation", reprints, including with various interactive elements can, on the one hand, be interpreted as "massification" of literature, and on the other - be an important element of functioning and actualisation of the national canon in its longevity. No wonder Rene Lachman calls intertextuality a literary form of memory that seeks to combine individual works into a coherent layer of culture [9]. What matters here is how and for what purpose such projects are implemented and to what extent they are a way of "linking" texts over time and a way of emphasising the valuable and paramount in culture. 
The suitability of reading practices for the formation of communities is obvious from another point of view on the subject of our study - the transformation of reading. These transformations take place both "from the book" it is about the emergence of new types of texts and ways to transmit and receive them; and "from the reader" through the formation of informal reading communities, reading work with the text: criticism, recommendations, amateur "rehashes" and other influences on the texts. Such joint cultural activities and active communication are a significant unifying component.

At the same time, these changes are interdependent: on the one hand, the book market stimulates new types of texts; on the other hand, users create reading practices through informal communication, which are eventually assimilated and used by the market. It is revealing that these new formats and practices are widely used not only by the book industry, but also by institutions designed to work with books and reading, including libraries. In fact, large national libraries stood at the origins of the new "revolution in reading" (by analogy with the theory of the revolution in reading of the mid-eighteenth century, proposed by Rolf Engelsing) [10], which consisted in digitising reading practices, on the one hand, and intensifying their interactivity on the other. These were the national libraries in the late twentieth - early twenty first century that eventually initiated major national and supranational projects: American Memory, positioned as a "resource for the digital preservation of American history and creativity, a reflection of the events, people, places, and ideas that shaped America"; digital resources formed within the framework of the European Union strategy, first of all Europeana, Manuscriptorium; domestic resource called Electronic Library "Ukrainica", aimed at the accumulation of "documents of state and national importance."

Such projects, and this is important in view of the topic of our research, combine new approaches to the presentation of texts and active work with meaningful texts. Working with such meaningful texts, the library, as a subject of creating a national narrative, continues to implement the memorial function on a new, digital level - selection for storage, providing access and retransmission of the community memory. In this way, libraries not only provide access to the community memory, but also participate in the creation of symbolic capital - the representation of national achievements.

The library broadcasts the national narrative, presenting meaningful texts through exhibition activities, the formation of electronic collections and libraries, representing them in global collections as an intellectual and cultural image of the nation. Strategies for formation of digital sources are based on the value of cultural heritage, the need to preserve the documentary memory of peoples and the constant support of formats in the face of changing technologies. It is worth agreeing with I.
Lobuzin's conclusion that "the key organisations in the creation of digital resources at the national level are national libraries, which is a natural consequence of the fact that these institutions have accumulated considerable experience in describing and managing documentary information of various formats." [11]. Systematic consideration of these projects allows us to trace their evolution from individual electronic collections to a comprehensive information resource (according to $\mathrm{K}$. Lobuzina) and the emergence of special interactive projects that involve users in their creation.

In the meantime, along with large-scale allembracing projects, memorial historical and cultural digital collections dedicated to individual figures or even books attract our attention. They are characterised by the integration of presented resources, a high level of information structuredness, its subordination to a single concept of knowledge representation [12].

One way to expand the audience of such library projects and ensure the convenience and accessibility of collections is to adapt library products and services to the active use in mobile devices. The so-called "mobilisation" of reading practices, which provides speed, convenience, personalisation and interactivity of access to user resources, has had an influence not only on library activities, but also affected all areas of the book and reading industry. It is mainly about the active implementation of mobile applications - computer programs created specifically for use on a mobile device and designed to perform some tasks as a tool of modern communications, in particular, the dissemination and promotion of scientific and socio-cultural information resources.

The attention is focused on the library aspects of this phenomenon due to several issues. Firstly, social significance is a determining factor for library projects, so it is through them that users gain access to resources of national and historical significance. Secondly, quite often application development projects go beyond the traditional library and have an interdisciplinary nature. Because of interaction of various institutions and organisations, unique information products are being created.

\section{DISCUSSION OF RESULTS}

Figures Earlier in our report, we dealt with iconic works and authors that form the literary canon. The importance of updating such texts in the public discourse was also emphasised, among other things - given the latest technological opportunities. With this in mind, we have analysed the existing mobile applications dedicated to iconic works for different national literatures and authors. The analysis showed that the representation of such projects could be grouped into three formats that differ in complexity and coverage. 
To start with, these are applications that are in fact mobile book collections, which usually provide paid access to new books on the book market, combined with the free ability to work with texts that have become classics of literature. Thus, classical literature ensures user interest that can give a commercial effect. Given that classical national literature is an integral part of educational programs of educational institutions, we conclude that its free presentation allows attracting young people to the users of applications.

Secondly, there is a whole group of applications that provide access to certain texts, usually iconic ones for national literatures: for the Ukrainian user these are projects dedicated to the works by Taras Shevchenko, Panas Myrnyi, Ivan Nechui-Levytskyi, Lesia Ukrainka; In general, world literature is widely represented: readers have the opportunity to work with applications on the works by William Shakespeare, George Byron, Arthur Conan Doyle, Jack London, Edgar Allan Poe, Charles Baudelaire, Jules Verne, Henryk Sienkiewicz, Adam Mickiewicz and others. These are usually mobile versions of e-books that provide easy access to work with individual texts and differ from the previous category only in the number of available books. The number of applications dedicated to the artistic activities of an iconic author (Shakespeare or Mickiewicz, for example) can range from tens to hundreds.

We consider it necessary to single out applications that correlate with the above-mentioned memorial historical and cultural digital collections. This category of applications is illustrated by the Ukrainian Kobzar by Taras Shevchenko, the English Shakespeare's Sonnets, the French Charles Baudelaire: Oeuvres complètes et annexes - 54 titres, and Jules Verne in Nantes, the Spanish Quijote interactivo, and the Colombian Eduardo Carranza. These applications include various categories, mainly biographical data about the writer, texts of his/her works with comments from literary critics, as well as rich illustrative material. The illustrations include facsimiles of the author's manuscripts, the first editions of works, in the case of Taras Shevchenko - reproductions of his paintings. Photos, letters, newspaper clippings are also included. Such collections are characterised by interactivity and multimediality. Thus, for example, the library of Shakespeare's sonnets is supplemented by video performances of recitations of sonnets by famous actors of theatre and cinema, which provides a stunning use of multimedia to bring a literary work to life. Acquaintance with the first edition of "Don Quixote", stored in the National Library of Spain, is accompanied by maps, a gallery of images and various characters of Don Quixote in the form of interactive magazines. The artistic work of Eduardo Carranza in an application created by the National Library of Colombia on the occasion of the 100th anniversary of the birth of the Colombian poet, is illustrated, among other things, by a time scale. The trilingual application dedicated to Jules
Verne is accompanied by geolocated maps and can be used as a tourist route. The functionality of the described applications includes the ability to create collections of works, systematisation of works by title or date or place of writing and other labels, keyword search.

These examples illustrate the integratedness of multimedia resources and a high level of information structuredness, which allows us to speak about the systematic presentation of knowledge. We would like to emphasise that since books and authors that form the national literary and, more broadly, cultural canon, are a mandatory component of the educational process, the format of such mobile applications has become quite convenient, accessible and in demand in educational processes.

Research has shown that e-book applications are more common today than complex collection applications. The number of downloads of applications by users on their mobile devices makes it possible to talk about the relevance and demand for such a resource.

In general, the analysis of mobile applications allows us to say that each country is trying to use mobile technologies to promote their outstanding writers, artists and works that have national and cultural, identity-related significance. It should be noted that such applications are created not only by government bodies (libraries, museums, institutes of memory), but also by publishers and ordinary connoisseurs of literature, fans of authors and works.

\section{CONCLUSIONS}

Thus, the connection between cultural practices and the formation and experience of identities, both personal and group, can be considered proven. Furthermore, since one of the most significant group identities is national identity, cultural practices at the national level are an important indicator of community cohesion, resilience, and adaptability.

Representation in the national culture of the body of significant texts and the development of literary and reading infrastructure - creation, publication, distribution, own reading and comprehension of works at different levels depending on age, professional involvement, reader engagement - is an important component of the cultural field.

The latest information technologies significantly affect the functioning of most cultural practices, including reading. The subjects of such processes are both individuals and groups or institutions. Among the latter, libraries should be singled out as cultural nonprofit public institutions. In recent decades, digital reading practices have actively promoted and ensured access to the national cultural heritage with high scientific and cultural quality. 
An essential feature of the relevant activities of libraries in recent years has been the creation of various mobile applications related to reading, often in collaboration with other educational or commercial institutions. Such applications differ from the usual access to texts on various media by expanding the possibilities of presenting texts relevant to national cultures through multimedia and interactivity.

Thus, we conclude that the influence of the latest elements of digital culture, particularly reading practices, on the formation of national identities as tools for

\section{REFERENCES}

[1] Dubrovina, L.A. Lobuzina K.V. Onyshchenko O.S. and Boriak, H.V. (2020), "Digital humanities and databases of cultural heritage in libraries of Ukraine", Manuscript and Book Heritage of Ukraine, iss. 25, pp. 290-309. DOI: $10.15407 /$ scine 17.01 .054

[2] Dubrovina, L. and Kovalchuk, H. (2016), "The Development of Digital Information Resources of Manuscript and Book Heritage in Vernadsky National Library of Ukraine", Library journal, no. 1, pp. 3-11.

[3] Konoval, L. (2016), "The experience of the national digital libraries' projects in the context of formation of electronic library «Ukrainika»”, Library journal, no. 2, pp. 11-14.

[4] Lobuzin, I. and Perenesiienko, I. (2020), "Electronic collections of Ukrainica in web environment: organization and technology of formation of resources of manuscript and book sources in V. I. Vernadskyi National Library of Ukraine", Manuscript and Book Heritage of Ukraine, iss. 25, pp. 324-336. DOI: $10.15407 /$ rks u. 25.324

[5] Anderson, B. (1991), "Imagined communities: reflections on the origin and spread of nationalism", VERSO, London, New York, pp. 42-47. involving individuals in the processes of shared experience and understanding of culture

\section{AUTHORS' CONTRIBUTIONS}

Yulia Polovynchak made conclusions concerning the influence of modern digital opportunities related to books and reading on the formation of a sense of belonging to the cultural and national community

Viktoriia Bondarenko researched mobile applications are considered one of the tools of wide and scientifically supported access to significant national texts.

[6] Jusdanis, G. (1991), "Belated Modernity and Aesthetic Culture: Inventing National Literature", Theory and History of Literature, vol. 81, pp. 4951.

[7] Romanenko O. (2019), "Generation: reader vs writer", Litaktsent, available at: http://litakcent.com/2019/04/25/pokolinnyachitach-vs-pismennik

[8] Polovynchak, Y. (2018), "Meaning-creating potential of entertaining fictional Internetdiscourse", Norwegian Journal of development of the International Science, vol. 19 (2), pp. 70-73.

[9] Lachmann, R. (2010), "Mnemonic and Intertextual Aspects of Literature", Cultural Memory Studies, pp. 301-310. DOI:10.1515/9783110207262.5.301

[10] Darnton, R. (1992), "History of Reading", New Perspectives on Historical Writing, Pennsylvania State University Press, pp. 140-168.

[11] Lobuzin, I. (2020), "International and national digital library projects: technological requirements and standards", Library Science. Record Studies. Informology, no. 1, pp. 79-87. DOI: $10.32461 / 2409-9805.1 .2017 .150251$

[12] Lobuzina, K. (2013), "Integrated Memorial Resource "The Vernadsky Electronic Library and Archives"', Ukraine of the XX century: culture, ideology, politics, vol. (18), pp. 24-30. 